\title{
Experiential Canalization of Behavioral Development: Theory
}

\author{
Gilbert Gottlieb \\ University of North Carolina at Greensboro
}

\begin{abstract}
Waddington's (1942) notion of canalization has been widely invoked in developmental psychology to conceptualize species-typical regularities in behavioral development as genetically determined. In contrast, a developmental systems view, such as the one described in the present article, sees the genes as only one component in a hierarchy of influences, all of which contribute to canalize behavioral development. A key issue is that genetic activity does not by itself produce finished traits; differentiation occurs as a consequence of events above as well as below the cellular level, necessarily involving factors in addition to genetic influences to canalize behavioral development. In exploring the possible experiential canalization of development, it was found that the mallard duck embryo's contact call plays a canalizing role in species-specific perceptual development (Gottlieb, 1991). Thus, normally occurring experience, in concert with genetic and other activities, can canalize behavioral development.
\end{abstract}

The concept of canalization has been utilized in several different ways in the psychological literature. Canalization was originally put forward by Holt (1931) to call attention to prenatal conditioning as a factor in narrowing down the initially diffuse or random nature of motor activity in the embryo or fetus. Holt saw the motor activity of the fetus and the infant as becoming organized through spatial and temporal contiguity learning that narrowed down originally diffuse neural pathways to a definite neural reflex arc. Thus, for Holt, canalization referred to the development of specific sensorimotor pathways out of an original multiplicity of such pathways; it was a label to capture the developmental-behavioral phenomenon of progression from diffuse to ordered or organized motor activity, with contiguity conditioning as the experiential mechanism whereby organized motor activity was achieved. Although Holt's concept of neural reflex circles to account for the development of grasping in the fetus and infant was an ingenious example of his point of view, it has remained an entirely speculative theoretical solution of primarily historical interest. Subsequent empirical studies in behavioral embryology have kept open the possibility that motor movements in the embryo and fetus of some species are patterned from the start, whereas in other species they appear to be random (see reviews in Gottlieb, 1970; Hamburger, 1973; Oppenheim, 1974).

A second, rather different, meaning of canalization was put

I have been working for a number of years on what I hope might be considered a comprehensive developmental systems view, an abstract of which is presented here. During the period that I have been working on this project, I have benefited from critical discussions with my closest colleagues. Among the many students and friends who have been kind enough to enthusiastically partake of these discussions, I would like to acknowledge, in chronological order, David Miller, Lynda Uphouse, Timothy Johnston, Robert Cairns, and Robert Lickliter. I also gratefully acknowledge current research support from $\mathrm{Na}$ tional Institute of Mental Health Grant MH-44813.

Correspondence concerning this article should be addressed to $\mathrm{Gil}$ bert Gottlieb, Department of Psychology, University of North Carolina, Greensboro, North Carolina 27412-5001. forward by Kuo (1976). For Kuo, canalization was a broadly applicable principle that says as development proceeds, the originally great range of behavioral potentials or plasticity narrows, signifying that the range of possibilities of behavioral development always exceeds the range of behavior that is actualized during the course of individual development. The channeling of behavior, and the correlated decrease of plasticity, over the course of ontogenesis is to be explained by the individual's particular developmental history, which, for Kuo, included biochemistry, physiology, and anatomy, as well as experience. Thus, Kuo's principle of canalization is a much broader idea than Holt's, and its appropriately descriptive intent would seem to mesh, in the most general terms, with almost everyone's idea of what happens during individual development. Like Holt, Kuo did not actually provide any explicit empirical or experimental support for what seems a face-valid proposition to many developmental psychologists and psychobiologists.

More recently, a number of psychologists have picked up on another, very different concept of canalization: the developmental geneticist Waddington's (1942) notion that early normal or species-typical physiological and anatomical development can withstand great assaults or perturbations and still return to (or remain on) its usual developmental pathway, thus producing the usual or normal phenotype. Waddington's concept of canalization says that usual developmental pathways are so strongly buffered (by genes; Waddington, 1957, p. 36, Figure 5) that normal or species-typical development can be only temporarily derailed. Waddington (1968) used the term chreod to express his idea more succinctly: a chreod, according to Waddington, is a "fated" or predetermined developmental pathway. Thus, for Waddington, embryonic anatomical and physiological development consists of a number of highly buffered (i.e., virtually fixed) endogenous pathways. Once again, the idea seems so face-valid no empirical support is presented for it, and the potential mechanism itself is described in only the most figurative or metaphorical terms. Individual development is characterized as a ball rolling down valleys of greater or lesser height that are said to make up the geography of the "epigenetic landscape" (Waddington, 1942, 1953, 1957, 1968). Because the epi- 
genetic landscape in which Waddington's developmental pathways are embedded is merely figurative or metaphorical, his concept of canalization is devoid of any empirical content and thus supplies us with no concrete understanding or hypotheses concerning the developmental process that is involved. The appeal of Waddington's notion, despite its conceptual and mechanistic emptiness, is testified to by its wide adoption in various developmental psychological models as a virtual synonym for what was previously called the innate, native, or maturational component in behavioral development (e.g., Fishbein, 1976; Kovach \& Wilson, 1988; Lumsden \& Wilson, 1980; Parker \& Gibson, 1979; Scarr-Salapatek, 1976). The strictly genetic determination of canalization is captured in the following quotations:

Canalization is the genetic limitation of phenotypic development to a few possible phenotypes rather than an infinite variety. . . The genetic restriction of possible phenotypes is a result of coadapted gene complexes (sets of genes that have evolved together) that buffer the developmental pattern against deviation outside of the normal, species range of variation. . .

The limitation of possible phenotypes to a few rather than many is a fact of genotypes' ranges of reaction. This concept can best be expressed developmentally in the notion of developmental pathways, which Waddington calls "creods." [sic] Behavioral creods are essentially similar to Piaget's notion of schemes, organized patterns of behavior that develop in characteristic ways. They represent the biases the organism has toward acquiring some rather than other forms of behavior. . .

These biases are undoubtedly genotypic. (Scarr-Salapatek, 1976, p. 63)

Waddington himself expressed the genetic determination of canalization as follows:

The epigenetic feed-back mechanisms on which canalization depends can, of course, be regarded as examples of gene interaction. Interaction between two allelomorphs is referred to by such terms as dominance, recessiveness, over-dominance, etc. Interactions between different loci come under the heading of epistasis. This is perhaps most usually thought of in terms of interaction between only two or three loci. We know, however, that in the development of any one organ very many genes may be involved, and in canalized epigenetic systems we are probably confronted with interactions between comparatively large numbers of genes. (Waddington, 1957, p. 131)

Fourteen years later, Waddington reiterated the strictly genetic determination of canalization as follows:

The degree to which each pathway is canalized or self-establishing is dependent on the particular alleles of the genes involved in it; and it can be altered by selection of a population either for alleles which fit better into the canalized system (and thus increase the organism's resistance of modification) or for alleles which do not integrate so well with the others (and thus lend to decreased resistance to external influences). (Waddington, 1971, pp. 20-21)

\section{Contemporary Developmental Theory}

In recent years, what might be called a "systems view" of individual development has been slowly catching on, both in biology and psychology. The systems view sees individual development as hierarchically organized into multiple levels (e.g., genes, cytoplasm, cell, organ, organ system, organism, behavior, environment) that can mutually influence each other. The traffic is bidirectional, neither exclusively bottom-up or topdown. (A formal treatment of hierarchy theory can be found in Salthe, 1985, especially Chapter 4.) Horowitz's (1987) recent review makes the systems case for developmental psychology, at least up to a point. (She still accepts some aspects of infant behavior as strictly genetically canalized or "hard wired" and makes no mention of the possible prenatal experiential influences on infant behavior) The geneticist Wright (1968) and the embryologists Bertalanffy (1933/1962) and Weiss (1939/1969) have long championed such a systems view for developmental genetics and developmental biology. The systems view includes developmental approaches and theories that have been called ecological (Bronfenbrenner, 1979), transactional (Dewey \& Bentley, 1949; Sameroff, 1983), contextual (Lerner \& Kaufman, 1985), interactive (Johnston, 1987; Magnusson, 1988), probabilistic epigenetic (Gottlieb, 1970), and individual-socioecological (Valsiner, 1987). For the present purposes, I think the metatheoretical developmental systems view can be fairly represented by the schematic presented in Figure 1.

The most important feature of the developmental systems view is the explicit recognition that the genes are an integral part of the system and that their activity (i.e., genetic expression) is affected by events at other levels of the system, including the environment of the organism. It is a well-accepted fact, for example, that hormones circulating in the blood make their way into the cell and into the nucleus of the cell, where they activate DNA that results in the production of protein (Gorbman, Dickhoff, Vigna, Clark, \& Ralph, 1983, p. 29, Fig. 1.13). The flow of hormones themselves can be affected by environmental events such as light, day length, nutrition, behavior, and so on, thereby completing the complete circle of mutually influential events from genes to environment.

Another fact about genes that has not yet made its way into the psychological literature is that genetic activity does not by itself produce finished traits such as blue eyes, arms, legs, or neurons. The problem of anatomical and physiological differentiation remains unsolved, but it is unanimously recognized as requiring influences above the strictly cellular level (i.e., cell-tocell interactions, positional influences, and so forth; Davidson, 1986; Edelman, 1988). Thus, the concept of the genetic determination of traits is truly outmoded, as is the concept of a genetically determined reaction range, used by Scarr-Salapatek (1976) in the quote above. (An insightful as well as witty critique of genetic determinism as applied to development is Oyama's [1985] The Ontogeny of Information.) The reaction-range concept has been replaced by the concept of a norm of reaction, which is essentially nonpredictive because it utilizes the developmental systems view, in which each new environment is expected to have a different influence on developmental outcomes that cannot be stated in advance of actual empirical investigation (Platt \& Sanislow, 1988). Therefore, although the

\footnotetext{
'I feel somewhat ungrateful in showing Waddington to be a rather surprisingly strict genetic determinist by quoting him. He is one of the few major thinkers in evolutionary biology who have felt that it is necessary to take into account developmental and organismic considerations, whereas most of the major figures in the making of modern synthesis (neo-Darwinism) have considered only natural selection and genetic variation to be the prime factors of importance in evolution.
} 


\section{BIDIRECTIONAL INFLUENCES}

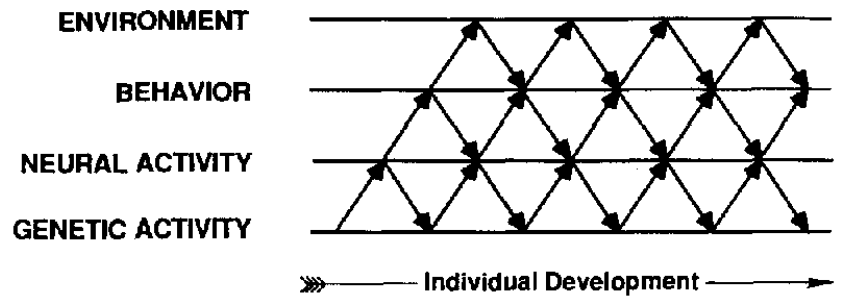

Figure 1. A simplified scheme of the developmental systems view, showing a hierarchy of four mutually interacting components in which there are "top-down" as well as "bottom-up" bidirectional influences.

genes remain an essential part of any developmental system and plasticity cannot be regarded as infinite, a thoroughgoing application of the norm-of-reaction concept may make the genetic limitations on development in practice, if not in principle, unknowable. Certainly, the appearance of mammalian dentition in birds (which otherwise never have teeth) under altered developmental circumstances provides striking testimony to the nonpredictability of genetic limitations on the phenotype (Kollar \& Fisher, 1980).

The above considerations have led me to wonder about the canalizing influence of events at other levels of the developmental system, because all levels of the system may be considered potentially equal in this respect in the developmental systems view depicted in Figure 1.

\section{Possible Experiential Canalization of Development}

In the usual interpretative framework for thinking about the canalization of development, the developing organism's interaction with its environment is viewed as the source of perturbations to the system against which the genes must buffer the developing organism to bring about a species-typical phenotypic outcome. The following quotation makes this point:

\footnotetext{
Ethologists have used various models of exactly how biological regulating mechanisms control the course of development, while allowing for the modification of development by the environment. One model, proposed by Waddington (1957), represents development as a ball rolling down an "epigenetic landscape." As the ball descends, this landscape becomes increasingly furrowed by valleys that greatly restrict the sideways movement of the ball. Slight perturbations from the developmental pathway can be corrected later through a "self-righting tendency," and the ball returns to its earlier groove. Thus, the general course of development is set, but some variation is possible because of particular environmental events. (Miller, 1989)
}

In the present account, I want to consider the possibility that the developing organism's usual or typical experience can play a canalizing role that not only brings about species-specific behavior but also prevents the developing organism from being susceptible to non-species-typical forms of stimulation. Thus, the particular theoretical model that $I$ have in mind is that normal experience helps to achieve species-specific behavioral development, and part of that process may involve making the developing organism unresponsive to extraspecific experiential influences.

\section{Experiential Canalization of Species-Specific Perceptual Development}

The concept of species-specific perception means that individuals of a given species respond in a characteristic way to certain objects (i.e, they respond only to certain patterns of sensory stimulation and not to others). Usually, these patterns of stimulation are provided by other members of the species. For example, young mallard ducklings and wood ducklings that have been hatched in incubators and never before exposed to maternal stimulation will selectively approach their own species's maternal assembly call in a simultaneous auditory choice test with the mallard and wood duck maternal calls. These calls differ on critical acoustic dimensions that mallard and wood ducklings find attractive. For the mallard ducklings, that feature is a call repetition rate of 4 notes/s $( \pm 0.5)$, and for the wood ducklings, the feature is a descending frequency modulation around $1200 \mathrm{~Hz}(+200 \mathrm{~Hz})$. It turns out that the ducklings' own vocalizations contain those features in an abstract way, so that when the ducklings are prevented from hearing their own or their siblings' vocalizations, they do not show their usual highly selective response to the maternal call of their own species (summarized in Gottlieb, 1981).

The fact that the ducklings have to hear their own (or siblings') vocalizations to show the species-specific responsiveness to their respective maternal calls raises the possibility that exposure to such vocalizations also plays a canalizing role in development. That is, in the absence of exposure to their own vocalizations, the ducklings may become susceptible to extraspecific maternal calls, whereas exposure to their own vocalizations may render them unsusceptible to extraspecific maternal stimulation. If this hypothesis were to be supported, it would demonstrate that normally occurring experience can canalize speciesspecific development. It is widely believed in biology and psychology that genes or the gene-directed maturation of the sense organs and nervous system are responsible for the canalization of species-specific development in humans and animals (e.g., Fishbein, 1976; Kovach \& Wilson, 1988; Lumsden \& Wilson, 1980; Marler, Zoloth, \& Dooling, 1981; Parker \& Gibson, 1979; Scarr-Salapatek, 1976; Waddington, 1942, 1957).

In sum, the developmental systems view gives rise to the idea that canalization can take place not only at the genetic level, but at all levels of the developing system (Figure 1), including the developing organism's usually occurring experiences. The experiential canalization of species-specific behavioral development has only rarely been experimentally demonstrated, so the work presented in my companion article (Gottlieb, 1991) was undertaken to document that point.

To briefly summarize the main findings of my accompanying empirical report (Gottlieb, 1991), exposure of mallard ducklings (Anas platyrhynchos) to their variable-rate contact call not only fosters species-specific perceptual development (i.e., ensuring selective responsiveness to the maternal call of the species), it also buffers the duckling from becoming responsive to social signals from other species. In the absence of exposure to the contact call, the duckling is capable of becoming 
attached to the maternal call of another species even in the presence of its own species call (in simultaneous auditorychoice tests). My previous demonstration of malleability in devocalized mallard ducklings (Gottlieb, 1987) involved the induction of a preference for either a chicken (Gallus gallus) maternal call or a wood duck (Aix sponsa) maternal call, in which case the birds were tested with the chicken versus wood duck calls, not the mallard maternal call. To be frank, I did not believe that it was possible to demonstrate malleability in the presence of the species-specific maternal call. It was only when I began to think of the possible canalizing effect of experience that it became apparent that devocalization might permit such a degree of malleability that exposure to an extraspecific maternal call would override the "innate" attractiveness of the species maternal call. Clearer thinking about what genes do and do not do in individual development gave rise to the idea that canalization must take place not only at the genetic level but at all levels of the developing system (Figure 1), including the developing organism's usually occurring experiences.

The fact that canalizing influences are potentially present at all levels of the developing system has not been widely appreciated. Rather, as shown by the quotes at the beginning of this article, the widespread tendency has been to ascribe canalization exclusively to geneticactivity, thereby short-circuiting developmental analysis and completely overlooking the various levels in the hierarchy of developmental systems that are necessary to produce a normal organism, species-typical behavior, and psychological functioning. It is all too common to read statements such as "the vertebrate brain is fully capable of encoding stimulus information by genetic instruction" (Kovach \& Wilson, 1988 , p. 659), which is merely a verbal way to close the tremendous gap between molecular biology and behavioral development. This also shows a lack of appreciation of what genes do and do not do during individual development. As it becomes more widely understood that differentiation of the nervous system (and all organ systems) takes place through influences above the level of the cell (Davidson, 1986; Edleman, 1987, 1988; Pritchard, 1986), a more thoroughgoing attitude or appreciation of developmental analysis will eventually supplant the verbalism of "genetic determination" and the empty metaphor of the "epigenetic landscape." I am genuinely sorry to sound so harshly critical, but I do believe that these ideas have provided impediments to thinking clearly about the need for conceptual and empirical analysis at all levels of the developmental systems hierarchy.

Because the particular developmental systems concept that I am advocating has not been spelled out before in the psychological literature, it would seem desirable to describe that view in greater detail here. (See Appendix.) The principal ideas concern the epigenetic characterization of individual development as an emergent, coactional, hierarchical system.

\section{The Developing Individual as an Emergent, Coactional, Hierarchical System}

The historically correct definition of epigenesis-the emergence of new structures and functions during the course of individual development-did not specify, even in a general way, how the emergent properties come into existence (Needham,
1959). Thus, there was still room for preformation-like thinking about development that I (Gottlieb, 1970) earlier labeled the predetermined conception of epigenesis, in contrast to a probabilistic conception (see Appendix for details). That epigenetic development is probabilistically determined by active interactions among its constituent parts is now so well accepted that epigenesis itself is sometimes defined as the interactionist approach to the study of individual development (e.g., Dewsbury, 1978; Johnston, 1987). That is a fitting tribute to the career-long labors of Kuo (1976), Schneirla (1961), and Lehrman (1970), the principal champions of the interaction idea in the field of psychology, particularly as it applies to the study of behavioral and psychological development.

Thus, it seems appropriate to offer a new definition of epigenesis that includes not only the idea of the emergence of new properties but also the idea that these emergent properties arise through reciprocal interactions (coactions) among already existing constituents. Somewhat more formally expressed, the new definition of epigenesis would say that individual development is characterized by an increase of complexity of organization (i.e., the emergence of new structural and functional properties and competencies) at all levels of analysis (molecular, subcellular, cellular, organismic) as a consequence of horizontal and vertical coactions among the organism's parts, including organism-environment coactions. Horizontal coactions are those that occur at the same level (gene-gene, cell-cell, tissuetissue, organism-organism), whereas vertical coactions occur at different levels (gene-cytoplasm, cell-tissue, behavioral activity-nervous system) and are reciprocal, meaning that they can influence each other in either direction, from lower to higher or from higher to lower levels of the developing system. For example, the sensory experience of a developing organism affects the differentiation of its nerve cells such that the more experience the more differentiation and the less experience the less differentiation. (For example, enhanced activity or experience during individual development causes more elaborate branching of dendrites and more synaptic contacts among nerve cells in the brain [Greenough \& Juraska, 1979].) ${ }^{2}$ Reciprocally, the more highly differentiated nervous system permits a greater degree of behavioral competency, and the less differentiated nervous system permits a lesser degree of behavioral competency. Thus, the essence of the probabilistic conception of epigenesis is the bidirectionality of structure-function relationships, as depicted in Figure 1 and the Appendix.

\section{Developmental Causality (Coaction)}

Behavioral (or organic or neural) outcomes of development are a consequence of at least two specific components of coaction (e.g., person-person, organism-organism, organism-environment, cell-cell, nucleus-cytoplasm, sensory stimulationsensory system, activity-motor behavior). The cause of development-what makes development happen-is the relationship of the two components, not the components themselves. Genes

\footnotetext{
${ }^{2}$ More recent research indicates that not only the amount of neural differentiation but the direction of such differentiation is influenced by sensory input to the cortex (Greenough \& Chang, 1988).
} 
in themselves cannot cause development any more than stimulation in itself can cause development. When we speak of coaction as being at the heart of developmental analysis or causality, what we mean is that we need to specify some relationship between at least two components of the developmental system. The concept used most frequently to designate coactions at the organismic level of functioning is experience: Experience is thus a relational term. As documented previously (Gottlieb, 1976), experience can play at least three different roles in anatomical, physiological, and behavioral development. It can be necessary to sustain already-achieved states of affairs (maintenance function), it can temporally regulate when a feature appears during development (facilitative function), and it can be necessary to bring about a state of affairs that would not appear unless the experience occurred (inductive function).

Because developing systems are by definition always changing in some way, statements of developmental causality must also include a temporal dimension describing when the experience or organic coactions occurred. For example, one of the earliest findings of experimental embryology had to do with the differences in outcome according to the time during early development when tissue was transplanted. When tissue from the head region of the embryo was transplanted to the embryo's back, if the transplantation occurred early in development, the tissue differentiated according to its new surround (i.e., it differentiated into back tissue), whereas if the transplant occurred later in development, the tissue differentiated according to its previous surround so that, for example, a third eye might appear on the back of the embryo. These transplantation experiments demonstrated not only the importance of time but aiso the essentially coactional nature of embryonic development.

\section{Significance of Coaction for Individual Development}

The early formulation by Weismann (1894) of the role of the hereditary material (what came to be called genes) in individual development held that different parts of the genome or genic system caused the differentiation of the different parts of the developing organism, so that there were thought to be genes for eyes, genes for legs, genes for toes, and so forth. Driesch's experiment (1929), in which he separated the first two cells of a sea urchin's development and obtained a fully formed sea urchin from each of the cells, showed that each cell contained a complete complement of genes. This means that each cell is capable of developing into any part of the body, a competency which was called equipotentiality or pluripotency in the jargon of the early history of experimental embryology and is called totipotency and multipotentiality in today's terms (e.g., DiBerardino, 1988). Each cell does not develop into just any part of the body, even though it has the capability of doing so. Each cell develops in accordance with its surround, so that cells at the anterior pole of the embryo develop into parts of the head, cells at the posterior pole develop into parts of the tail end of the body, cells in the foremost lateral region of the embryo develop into forelimbs, those in the hindmost lateral region develop into hindlimbs, the dorsal area of the embryo develops into the back, and so on.

Although we do not know what actually causes cells to differentiate appropriately according to their surround, we do know that it is the cell's interaction with its surround, including other cells in that same area, that causes the cell to differentiate appropriately. The actual role of genes (DNA) is not to produce an arm, a leg, or fingers, but to produce protein (through the coactions inherent in the formula DNA $\leftrightarrow$ RNA $\leftrightarrow$ protein in the Appendix). The specific proteins produced by the DNA-RNAcytoplasm coaction are influenced by coactions above the level of DNA-RNA coaction.

In sum, when certain scientists refer to behavior or any other aspect of organismic structure or function as being "genetically determined," they are not mindful of the fact that genes synthesize protein in the context of a developmental system of higher influences. Thus, for example, as experiments on the early development of the nervous system have demonstrated, the amount of protein synthesis is regulated by neural activity, once again demonstrating the bidirectionality and coaction of influences during individual development (e.g., Born \& Rubel, 1988; summaries in Changeux \& Konishi, 1987).

\section{The Hierarchical Systems View}

Much has been written about the holistic or systems nature of individual development, beginning as early as Smuts (1926). In fact, there is no other way to envisage the manner in which development must occur if a harmoniously functioning, fully integrated organism is to be its product. Earlier, I alluded to the writings of the geneticist Wright and the embryologist Weiss, which very well portray the major components of the developing individual as an emergent, coactional, hierarchical system. So far, I have dealt with the concepts of emergence and coaction as they pertain to the development of individuals. The notion of hierarchy, as it applies to individual development, simply means that coactions occur vertically, as well as horizontally, in all developmental systems. All of the parts of the system are capable of influencing all of the other parts of the system, however indirectly that influence may manifest itself. Consonant with Wright's and Weiss's depiction of the developmental system, the organismic hierarchy proceeds from the lowest level, that of the genome or DNA in the nucleus, to the nucleus in the cytoplasm of the cell, to the cell in a tissue, to the tissue in an organ, the organ in an organ system, the organ system in an organism, the organism in an environment of other organisms and physical features, the environment in an ecosystem, and so on back down through the hierarchical developmental system (review by Grene, 1987; Salthe, 1985).

A dramatic developmental effect traversing the many levels from the environment back to the cytoplasm of the cell was shown by the experiments of Jollos (1934) in the 1930s and Ho in the 1980s. In Ho's (1984) experiment, an extraorganismic environmental event such as a brief period of exposure to ether occurring at a particular time in embryonic development can alter the cytoplasm of the cell in such a way that the protein produced by DNA-RNA-cytoplasm coaction eventually becomes a second set of wings (an abnormal "bithorax" condition) in place of the halteres (balancing organs) on the body of an otherwise normal fruitfly. Obviously, it is very likely that "signals" have been altered at various levels of the developmental hierarchy to achieve such an outcome. (Excellent texts that describe the many different kinds of coactions that are a neces- 
sary and normal part of embryonic development are Wessells's [1977] Tissue Interactions and Development and, more recently, for the nervous system, Edelman's [1987] Neural Darwinism.)

When the cytoplasm of the cell is altered, as in the experiments of Jollos and $\mathrm{Ho}$, the effect is transgenerational, such that the untreated daughters of the treated mothers continue for a number of generations to produce bithorax offspring and do so even when mated with males from untreated lines. Such a result has evolutionary as well as developmental significance, which, to this date, has been little exploited because the neo-Darwinian, modern synthesis does not yet have a role in evolution for anything but changes in genes and gene frequencies in evolution: Epigenetic development above the level of the genes has not yet been incorporated into the modern synthesis (Futuyma, 1988: Lovtrup, 1987).

Another remarkable organism-environment coaction occurs routinely in coral reef fish. These fish live in spatially well-defined, social groups in which there are many females and few males. When a male dies or is otherwise removed from the group, one of the females initiates a sex reversal over a period of about two days, in which she develops the coloration, behavior, and gonadal physiology and anatomy of a fully functioning male (Shapiro, 1981). Such sex reversals keep the sex ratios about the same in social groups of coral reef fish. Apparently, it is the higher ranking females that are the first to change their sex, and this inhibits sex reversal in lower ranking females in the group. Sex reversal in coral reef fish provides an excellent example of the vertical dimension of developmental causality.

The completely reciprocal or bidirectional nature of the vertical or hierarchical organization of individual development is nowhere more apparent than in the responsiveness of cellular or nuclear DNA itself to behaviorally mediated events originating in the external environment of the organism (e.g., Hydén \& Egyházi, 1962, 1964). The major theoretical point is that the genes are part of the developmental system in the same sense as other components (cell, tissue, organism), so genes must be susceptible to influence from other levels during the process of individual development. DNA produces protein and cells are composed of protein, so from a comparative-evolutionary perspective, there must be a high correlation among the size of cells, the amount of protein, and the quantity of DNA, and there must also be a high correlation among the number of cells, the amount of protein, and the quantity of DNA-and so there is (Cavalier-Smith, 1985; Mirsky \& Ris, 1951).

For our developmental-behavioral/psychological purposes, it is most interesting to focus on the developing brain, and we find that there is the expected correlation between the number of brain cells and the quantity of DNA (Zamenhof \& van Marthens, 1978, 1979). From the present point of view, it is significant that the amount of protein in the developing rodent and chick brain is influenced by two sorts of environmental input: nutrition and sensorimotor experience. Undernutrition and "supernutrition" produce newborn rats and chicks with lower and higher quantities of cerebral protein, respectively (Zamenhof \& van Marthens, 1978, 1979). Similar cerebral consequences are produced by extreme variations (social isolation, environmental enrichment) in sensorimotor experience during the postnatal period (Renner \& Rosenzweig, 1987).

Because the route from DNA to protein is through the me- diation of RNA (DNA $\rightarrow$ RNA $\rightarrow$ protein), it is significant for the present theoretical viewpoint that social isolation and environmental enrichment produce alterations in the complexity (or diversity) of RNA sequences in the brains of rodents. (RNA complexity or diversity refers to the total number of nucleotides of individual RNA molecules.) Environmental enrichment produces an increase in the diversity of RNA sequences, whereas social isolation results in a significantly reduced degree of RNA diversity (Grouse, Schrier, Letendre, \& Nelson, 1980; Uphouse \& Bonner, 1975). Because the diversity of RNA sequences (or lack of it) is a direct consequence of DNA activity, the enriched and deprived environments affect DNA activity. These experientially produced alterations in RNA diversity are specific to the brain. When other organs are examined (e.g., the liver), no such changes are found.

\section{Nonlinear Causality}

Because of the emergent nature of epigenetic development, another important feature of developmental systems is that causality is often not "linear" or straightforward. In developmental systems, the coaction of $X$ and $Y$ often produces $W$ rather than more of $X$ or $Y$ or some variant of $X$ or $Y$. Another, perhaps clearer, way to express this same idea is to say that developmental causality is often not obvious. For example, in my own research described earlier, I found that mallard duck embryos had to hear their own vocalizations prior to hatching if they were to show their usual highly specific behavioral response to the mallard maternal assembly call after hatching. If the mallard duck embryo was deprived of hearing its own or siblings' vocalizations, it lost its species-specific perceptual specificity and became as responsive to the maternal assembly calls of other species as to the mallard hen's call. To the human ear, the embryo's vocalizations sound nothing like the maternal call. It turned out, however, that there are certain rather abstract acoustic ingredients in the embryonic vocalizations that correspond to critical acoustic features that identify the mallard hen's assembly call. In the absence of experiencing those ingredients, the mallard duckling's auditory perceptual system is not completely "tuned" to those features in the mallard hen's call, and the ducklings respond to the calls of other species that resemble the mallard in these acoustic dimensions. The intricacy of the developmental causal network revealed in these experiments proved to be striking. Not only must the duckling experience the vocalizations as an embryo (the experience is ineffective after hatching), but the embryo must experience embryonic vocalizations. That is, the embryonic vocalizations change after hatching and no longer contain the proper ingredients to tune the embryo to the maternal call (Gottlieb, 1985).

Prenatal nonlinear causality is also nonobvious because the information, outside of experimental laboratory contexts, is usually not available to us. For example, the rate of adult sexual development is retarded in female gerbils that were adjacent to a male fetus during gestation (Clark \& Galef, 1988). To further compound the nonobvious, the daughters of late-maturing females are themselves retarded in that respect-a transgenerational effect.

In a very different example of nonobvious and nonlinear developmental causality, Cierpal and McCarty (1987) found 
that the so-called spontaneously hypertensive (SHR) rat strain used as an animal model of human hypertension is made hypertensive by coacting with their mothers after birth. When SHR rat pups are suckled and reared by normal rat mothers after birth, they do not develop hypertension. It appears that there is a "hyperactive" component in SHR mothers' maternal behavior that causes SHR pups to develop hypertension (Myers, Brunelli, Shair, Squire, \& Hofer, 1989; Myers, Brunelli, Squire, Shindeldecker, \& Hofer, 1989). The highly specific coactional nature of the development of hypertension in SHR rats is shown by the fact that normotensive rats do not develop hypertension when they are suckled and reared by SHR mothers. Thus, although SHR rat pups differ in some way from normal rat pups, the development of hypertension in them nonetheless requires an interaction with their mother; it is not an inevitable outcome of the fact that they are genetically, physiologically, or anatomically different from normal rat pups. This is a good example of the relational aspect of the definition of experience and developmental causality offered earlier. The cause of the hypertension in the SHR rat strain is not in the SHR rat pups or in the SHR mothers but in the nursing relationship between the SHR rat pups and their mothers.

Another example of a nonlinear and nonobvious developmental experience undergirding species-typical behavioral development is Wallman's (1979) demonstration that if chicks are not permitted to see their toes during the first two days after hatching, they do not eat or pick up mealworms as chicks normally do. Instead, the chicks stare at the mealworms. Wallman suggested that many features of the usual rearing environment of infants may offer experiences that are necessary for the expression of species-typical behavior.

\section{The Unresolved Problem of Differentiation}

The nonlinear, emergent, coactional nature of individual development is well exemplified by the phenomenon of differentiation, whereby a new kind of organization comes into being by the coaction of preexisting parts. If genes directly caused parts of the embryo, then there would be less of a problem in understanding differentiation. Because the route from gene to mature structure or organism is not straightforward, however, differentiation poses a significant intellectual puzzle. The problem of differentiation also involves our limited understanding of the role of genes in development.

It has been recognized since the time of Driesch's (1908/ 1929) earth-shaking experiments demonstrating the genetic equipotentiality of all cells of the organism that the chief problem of understanding development has been that of understanding why originally equipotential cells actually do become different in the course of development (i.e., how it is that they differentiate into cells that form the tissues of very different organ systems). The problem of understanding development thus became the problem of understanding cellular differentiation. We still do not understand differentiation, and it is quite telling of the immense difficulty of the problem that today's theory of differentiation is very much like the necessarily vaguer theories put forth by Wilson in 1896 and Morgan in 1934 (reviewed in Davidson, 1986), namely, that ultimate or eventual cellular differentiation is influenced by an earlier coaction of the genetic material in the nucleus of the cell with particular regions of the cytoplasm of the cell. Some of the vagueness has been removed in recent years by the actual determination of regional differences in the cytoplasm (extensively reviewed by Davidson, 1986). Thus, the protein resulting from locale or regional differences of nucleocytoplasmic coaction is biochemically distinct, which, in some as yet unknown way, influences or biases its future course of development. For example, protein with the same or similar biochemical make-up may stay together during cellular migration during early development and thus eventually come to form a certain part of the organism by the three-dimensional spatial-field considerations of the embryo mentioned earlier.

Although the actual means or mechanisms by which some cells become one part of the organism and others become another part are still unresolved, we do have a name for the essential coactions that cause cells to differentiate: they are called embryonic inductions (recent review in Hamburger, 1988). The nonlinear hallmark of developmental causality is well exemplified by embryonic induction, in which one kind of cell (A), coacting with a second kind of cell (B), produces a third kind of cell (C). For example, if left in place, cells in the upper one-third of an early frog embryo differentiate into nerve cells; if removed from that region, those same cells can become skin cells. Equipotentiality and the critical role of spatial position in determining differentiation in the embryo are well captured in a quotation from the autobiography of Hans Spemann, the principal discoverer of the phenomenon of embryonic induction: "We are standing and walking with parts of our body which could have been used for thinking if they had been developed in another position in the embryo" (translated by Hall, 1988, p. 174). It might have been even more striking - and equally correct-if Spemann had elected to say, "We are sitting with parts of our body which could have been used for thinking. . . ."

Even if we do not yet have a complete understanding of differentiation, the facts at our disposal show us that epigenesis is correctly characterized as an emergent, coactional, hierarchical system that results in increasingly complex biological, behavioral, and psychological organization during the course of individual development.

In summary, genes are part of the developmental system and are not inviolate or immune to influences from other levels of the system, as one sometimes reads in the biological literature from Weismann (1894) to the present day. For example, the eminent evolutionary biologist Mayr has written, "The DNA of the genotype does not itself enter into the developmental pathway but simply serves as a set of instructions" (Mayr, 1982, p. 824). Rather to the contrary, as has been demonstrated repeatedly since Hydén and Egyházi's behavioral research in the early $1960 \mathrm{~s}$, individual experience alters gene expression during ontogenetic development. It would seem of great importance for developmental psychologists (one wants to say all psychologists) to be fully aware of this momentous change in our knowledge of genetic activity during individual development, along with the fact that genes do not by themselves produce differentiated phenotypic traits. One can hope that the immense gap between molecular biology and developmental psychology will one day be filled with facts, as well as with valid concepts. 


\section{References}

Bertalanffy, L. von. (1962). Modern theories of development: An introduction to theoretical biology. New York: Harper \& Row. (Original work published in German in 1933)

Born, D. E., \& Rubel, E. W. (1988). Afferent influences on brain stem auditory nuclei of the chicken: Presynaptic action potentials regulate protein synthesis in nucleus magnocellularis neurons. Journal of Neuroscience, 8, 901-919.

Bronfenbrenner, U. (1979). The ecology of human development: Experiments by nature and design. Cambridge, MA: Harvard University Press.

Cavalier-Smith, T. (1985). Cell volume and the evolution of eukaryote genome size. In T. Cavalier-Smith (Ed.), The evolution of genome size (pp. 105-184). New York: Wiley.

Changeux, J.-P., \& Konishi, M. (Eds.). (1987). The neural and molecular bases of learning. New York: Wiley.

Cierpal, M. A., \& McCarty, R. (1987). Hypertension in SHR rats: Contribution of maternal environment. American Journal of Physiology 253, 980-984.

Clark, N. M., \& Galef, B. G. (1988). Effects of uterine position on rate of sexual development in female mongolian gerbils. Physiology \& $\mathrm{Be}$ havior, 42, 15-18.

Davidson, E. (1986). Gene activity in early development. San Diego, CA: Academic Press.

Dewey, J., \& Bentley, A. F. (1949). Knowing and the known. Boston: Beacon.

Dewsbury, D. A. (1978). Comparative animal behavior. New York: McGraw-Hill.

DiBerardino, M. A. (1988). Genomic multipotentiality of differentiated somatic cells. In G. Eguchi, T. S. Okada, \& L. Saxén (Eds.), Regulatory mechanisms in developmental processes (pp. 129-136). Amsterdam: Elsevier.

Driesch, H. (1929). The science and philosophy of the organism (2nd rev. ed.). London: Black.

Edelman, G. M. (1987). Neural Darwinism: The theory of neuronal group selection. New York: Basic Books.

Edelman, G. M. (1988). Topobiology: An introduction to molecular biology. New York: Basic Books.

Fishbein, H. D. (1976). Evolution, development, and children's learning. Pacific Palisades, CA: Goodyear.

Futuyma, D. J. (1988). Sturm und Drang and the evolutionary synthesis. Evolution, 42, 217-226.

Gorbman, A., Dickhoff, W. W., Vigna, S. R., Clark, N. B., \& Ralph, C. L. (1983). Comparative endocrinology. New York: Wiley.

Gottlieb, G. (1970). Conceptions of prenatal behavior. In L. R. Aronson, E. Tobach, D. S. Lehrman, \& J. S. Rosenblatt (Eds.), Development and evolution of behavior (pp. 111-137). San Francisco: Freeman.

Gottlieb, G. (1976). Conceptions of prenatal development: Behavioral embryology. Psychological Review, 83, 215-234.

Gottlieb, G. (1981). Roles of early experience in species-specific perceptual development. In R. N. Aslin, J. R. Alberts, \& M. R. Petersen (Eds.), Development of perception (Vol, 1, pp. 5-44). San Diego, CA: Academic Press.

Gottlieb, G. (1985). Development of species identification in ducklings: XI. Embryonic critical period for species-typical perception in the hatchling. Animal Behaviour, 33, 225-233.

Gottlieb, G. (1987). Development of species identification in ducklings: XIII. A comparison of malleable and critical periods of perceptual development. Developmental Psychobiology, 20, 393-404.

Gottlieb, G. (1991). Experiential canalization of behavioral development: Results. Developmental Psychology, 27, 35-39.

Greenough, W. T., \& Chang, F. L. F. (1988). Dendritic pattern formation involves both oriented regression and oriented growth in the barrels of mouse somatosensory cortex. Developmental Brain Research, 43, 148-152.

Greenough, W. T., \& Juraska, J. M. (1979). Experience-induced changes in brain fine structure: Their behavioral implications. In M. E. Hahn, C. Jensen, \& B. C. Dudek (Eds.), Development and evolution of brain size (pp. 296-320). San Diego, CA: Academic Press.

Grene, M. (1987). Hierarchies in biology. American Scientist, 75, 504 510.

Grouse, L. D., Schrier, B. K., Letendre, C. H., \& Nelson, P. G. (1980). RNA sequence complexity in central nervous system development and plasticity. Current Topics in Developmental Biology, 16, 381-397.

Hall, B. K. (1988). The embryonic development of bone. American Scientist. 76, 174-181.

Hamburger, V. (1973). Anatomical and physiological basis of embryonic motility in birds and mammals. In G. Gottlieb(Ed.), Behavioral embryology (pp. 51-76). San Diego, CA: Academic Press.

Hamburger, V. (1988). The heritage of experimental embryology: Hans Spemann and the organizer. New York: Oxford University Press.

Ho, M.W. (1984). Environment and heredity in development and evolution. In M.-W. Ho and P. T. Saunders (Eds.), Beyond neo-Darwinism: An introduction to the new evolutionary paradigm (pp. 267-289). San Diego, CA: Academic Press.

Holt, E. B. (1931). Animal drive and the learning process (Vol. 1). New York: Holt.

Horowitz, F. D. (1987). Exploring developmental theories: Toward a structural/behavioral model of development. Hillsdale, NJ: Erlbaum.

Hydén, H., \& Egyházi, E. (1962). Nuclear RNA changes of nerve cells during a learning experiment in rats. Proceedings of the National Academy of Sciences USA, 48, 1366-1373.

Hydén, H., \& Egyházi, E. (1964). Changes in RNA content and base composition in cortical neurons of rats in a learning experiment involving transfer of handedness. Proceedings of the National Academy of Sciences USA, 52, 1030-1035.

Johnston, T. D. (1987). The persistence of dichotomies in the study of behavioral development. Developmental Review, 7, 149-182.

Jollos, V. (1934). Inherited changes produced by heat treatment in $\mathrm{Dro}-$ sophila melanogaster. Genetics, 16, 476-494.

Kollar, E. J., \& Fisher, C. (1980). Tooth induction in chick epithelium: Expression of quiescent genes for enamel synthesis. Science, 207. 993-995.

Kovach, J. K., \& Wilson, G. (1988). Genetics of color preferences in quail chicks: Major genes and variable buffering by background genotype. Behavioral Genetics, 18, 645-661.

Kuo, Z.Y. (1976). The dynamics of behavior development (rev. ed.). New York: Plenum Press.

Lehrman, D. S. (1970). Semantic and conceptual issues in the naturenurture problem. In L. R. Aronson, D. S. Lehrman, E. Tobach, \& J. S. Rosenblatt (Eds.), Development and evolution of behavior (pp. 17-52). San Francisco: Freeman.

Lerner, R. M., \& Kaufman, M. B. (1985). The concept of development in contextualism. Developmental Review, 5, 309-333.

Løvtrup, S. (1987). Darwinism: Refutation of a myth. Beckenham, England: Croom Helm.

Lumsden, C. J., \& Wilson, E. O. (1980). Translation of epigenetic rules of individual behavior into ethnographic patterns. Proceedings of the National Academy of Sciences USA, 77, 4382-4386.

Magnusson, D. (1988). Individual development from an interactional perspective: $A$ longitudinal study. Hillsdale, $\mathrm{NJ}$ : Erlbaum.

Marler, P., Zoloth, S., \& Dooling, R. (1981). Innate programs for perceptual development: An ethological view. In E. Gollin (Ed), Developmental plasticity (pp. 135-172). San Diego, CA: Academic Press.

Mayr, E. (1982). The growth of biological thought. Cambridge, MA: Harvard University Press. 
Miller, P. H. (1989). Theories of developmental psychology (2nd ed.). San Francisco: Freeman.

Mirsky, A. E., \& Ris, H. (1951). The desoxyribonucleic acid content of animal cells and its evolutionary significance. Journal of General Physiology, 34, 451-462.

Myers, M. M., Brunelli, S. A., Shair, H. M., Squire, J. M., \& Hofer, M. A. (1989). Relationships between maternal behavior of SHR and WKY dams and adult blood pressures of cross-fostered $F_{1}$ pups. Developmental Psychobiology. 22, 55-67.

Myers, M. M., Brunelli, S. A., Squire, J. M., Shindeldecker, R. D., \& Hofer, M. A. (1989). Maternal behavior of SHR rats and its relationships to offspring blood pressure. Developmental Psychobiology, 22, 29-53.

Needham, J. (1959), A history of embryology. New York: Abelard-Schuman.

Oppenheim, R. W. (1974). The ontogeny of behavior in the chick embryo. Advances in the Study of Behavior, 5, 133-172.

Oyama, S. (1985). The ontogeny of information. Cambridge, England: Cambridge University Press.

Parker, S. T., \& Gibson, K. R. (1979). A developmental model for the evolution of language and intelligence in early hominids. Behavioral and Brain Sciences, 2, 367-408.

Platt, S. A., \& Sanislow, C. A. (1988). Norm-of-reaction: Definition and misinterpretation of animal research. Journal of Comparative Psychology, 102, 254-261.

Pritchard, D. J. (1986). Foundations of developmental genetics. London: Taylor \& Francis.

Renner, M. J., \& Rosenzweig, M. R. (1987). Enriched and impoverished environments. New York: Springer.

Salthe, S. N. (1985). Evolving hierarchical systems: Their structure and representation. New York: Columbia University Press.

Sameroff, A. J. (1983). Developmental systems: Contexts and evolution. In P. H. Mussen (Series Ed.) \& W. Kessen (Ed.), Handbook of child psychology: Vol. 1. History, theory, and methods (4th ed., pp. 237-294). New York: Wiley.

Scarr-Salapatek, S. (1976). Genetic determinants of infant development: An overstated case. In L. Lipsitt (Ed.), Developmental psychobiology: The signiflcance of infancy (pp. 59-79). Hillsdale, NJ: Erlbaum.

Schneirla, T. C. (1961). Instinctive behavior, maturation-Experience and development. In B. Kaplan \& S. Wapner (Eds.), Perspectives in psychological theory: Essays in honor of Heinz Werner (pp. 303-334). New York: International Universities Press.

Shapiro, D. Y. (1981). Serial female sex changes after simultaneous removal of males from social groups of a coral reef fish. Science, 209 , 1136-1137.

Smuts, J. C. (1926). Holism and evolution. London: Macmillan.

Uphouse, L. L., \& Bonner, J. (1975). Preliminary evidence for the effects of environmental complexity on hybridization of rat brain RNA to rat unique DNA. Developmental Psychobiology, 8, 171-178.

Valsiner, J. (1987). Culture and the development of children's action. New York: Wiley.

Waddington, C. H. (1942). Canalization of development and the inheritance of acquired characters. Nature, 150, 563-564.

Waddington, C. H. (1953). Genetic assimilation of an acquired character. Evolution, 7, 118-126.

Waddington, C. H. (1957). The strategy of the genes. London: Allen \& Unwin.

Waddington, C. H. (1968). The basic ideas of biology. In C. H. Waddington (Ed), Towards a theoretical biology: Vol. 1. Prolegomena (pp. 1-32). Chicago: Aldine.

Waddington, C. H. (1971). Concepts of development. In E. Tobach, L. R. Aronson, \& E. Shaw (Eds.), The biopsychology of development (pp. 17-23). San Diego, CA: Academic Press.

Wallman, J. (1979). A minimal visual restriction experiment: Preventing chicks from seeing their feet affects later responses to mealworms. Developmental Psychobiology, 12, 391-397.

Weismann, A. (1894). The effect of external influences upon development. London: Frowde.

Weiss, P. (1969). Principles of development. New York: Hafner. (Original work published 1939)

Wessells, N. K. (1977). Tissue interactions and development. Menlo Park, CA: Benjamin.

Wright, S. (1968). Evolution and the genetics of populations; Vol. 1. Genetic and biometric foundations. Chicago: University of Chicago Press.

Zamenhof, S., \& van Marthens, E. (1978). Nutritional influences on prenatal brain development. In G. Gottlieb (Ed), Early influences (pp. 149-186). San Diego, CA: Academic Press.

Zamenhof, S., \& van Marthens, E. (1979). Brain weight, brain chemical content, and their early manipulation. In M. E. Hahn, C. Jensen, \& B. C. Dudek (Eds.), Development and evolution of brain size (pp. 164185). San Diego, CA: Academic Press. 
Appendix

Two Versions of Epigenetic Development

Predetermined Epegenesis:

Unidirectional Structure-Function Development

Genetic activity (DNA $\rightarrow$ RNA $\rightarrow$ protein) $\rightarrow$

structural maturation $\rightarrow$ function, activity, or experience.

Probabilistic Epigenesis:

Bidirectional Structure-Function Development

Genetic activity (DNA $\leftrightarrow$ RNA $\leftrightarrow$ protein) $\leftrightarrow$

structural maturation $\leftrightarrow$ function, activity, or experience.

As applied to the nervous system, structural maturation refers to neurophysiological and neuroanatomical development, principally the structure and function of nerve cells and their synaptic interconnections. The unidirectional structurefunction view assumes that genetic activity gives rise to structural maturation that then leads to function in a nonreciprocal fashion, whereas the bidirectional view holds that there are constructive reciprocal relations among genetic activity, maturation, and function. In the unidirectional view, the activity of genes and the maturational process are pictured as relatively encapsulated or insulated, so that they are uninfluenced by feedback from the maturation process or function, whereas the bidirectional view assumes that genetic activity and maturation are affected by function, activity, or experience. The bidirectional or probabilistic view applied to the usual unidirectional formula calls for arrows going back to genetic activity to indicate feedback serving as signals for the turning off and turning on of genetic activity to manufacture protein. The usual view calls for genetic activity to be regulated by the genetic system itself in a strictly feedforward manner. That the bidirectional view is correct all the way to the level of DNA is evidenced by the experimental results of researchers such as Zamenhof and van Marthens (1978), Uphouse and Bonner (1975), Grouse, Schrier, Letendre, and Nelson (1980), and Hydén and Egyházi $(1962,1964)$, among others.

(Here and in the text I have presented the DNA $\rightarrow$ RNA $\rightarrow$ protein pathway in a somewhat oversimplified manner, disregarding the fact that a number of crucial events intervene between RNA and protein formation. In fact, according to Pritchard [1986], dozens of known factors intervene between RNA activity and protein synthesis. Thus, it is an oversimplification to imply that DNA and RNA alone produce specific proteins; other factors [e.g., cytoplasm] contribute to the specificity of the protein.)

Received October 10,1989

Revision received March 5, 1990

Accepted April 13, 1990 